\title{
Effect on Testosterone Production in Sprague-Dawley Rats of Gastrodia and Bee Pollen
}

\author{
In-Pyo Hong, Soon-Ok Woo and Jae-Seon Jang*† \\ National Academy of Agricultural Science, Rural Development Administration, Suwon, Korea \\ *Department of Food \& Nutrition, Gachon Unversity, Incheon, Korea
}

\begin{abstract}
Objectives: We investigated the effects of Korean gastrodia and bee pollen on testosterone production in Sprague-Dawley rats.

Methods: This study measured the body weight, consumption of food and water, and serum testosterone concentration in SD rats fed for four weeks with gastrodia and bee pollen.

Results: The average body weights after four weeks were $375 \pm 2 \mathrm{~g}$ for the control group, $358 \pm 3 \mathrm{~g}$ for gastrodia consumption, and $354 \pm 2 \mathrm{~g}$ and $367 \pm 8 \mathrm{~g}$ for acorn pollen and Siberian gooseberry pollen, respectively. The average food consumption in SD rats over the four weeks in the control was $23.6 \mathrm{~g}$ for gastrodia consumption, $24.3 \mathrm{~g}$ and $24.9 \mathrm{~g}$ for acorn pollen and Siberian gooseberry pollen, respectively. The average water consumption over the four weeks was $38.33 \mathrm{ml}$ in the control group, $35.0 \mathrm{ml}$ for gastrodia treatment, and $33.3 \mathrm{ml}$ and $33.3 \mathrm{ml}$ for acorn pollen and Siberian gooseberry pollen treatment, respectively. The testosterone secretion levels in the serum of male rats were increased by gastrodia, acorn pollen, and Siberian gooseberry pollen $(2.68,3.00$, and $3.28 \mathrm{pg} / \mathrm{ml}$, respectively) compared to the control group $(2.23 \mathrm{pg} / \mathrm{ml})$.

Conclusions: These results suggest that gastrodia or bee pollen may be developed as a complementary medicine to improve sexual hormone production.
\end{abstract}

Keywords: gastrodia, acorn pollen, siberian gooseberry pollen, testosterone

\section{Introduction}

Testosterone plays an essential role in controlling male sexual activities and reproductive functions. It levels peak in the late teens to early twenties and decline slowly but steadily after that. Testosterone belongs to a class of hormones called androgens, which are those steroid hormones that controlling male reproductive function. ${ }^{1)}$ Some men suffer from insufficient secretion of testosterone due to physical, social, and psychological factors. ${ }^{2,3)}$ This often leads to decreased sexual function and desire, infertility, impotence or erectile dysfunction, decreased muscle mass and even hair loss. For decades, the injection of testosterone to restore reproductive function has been applied to men with insufficient testosterone secretion. ${ }^{4)}$ On the other hand, alternative medicines involving plants, fungi, and insects are also used to enhance sexuality. ${ }^{5}$ However, the scientific evidence related to the mechanisms or efficacy of these alternatives is often unconvincing. Recently, Korean researchers have studied complementary medicines featuring silkworms or Cordycpes mushrooms to improve secretion of sexual hormones. ${ }^{6-9)}$ Gastrodia (Gastrodia elata BL.) is one of the most important oriental herbal medicines in thousands of years because it possesses many important pharmacological activities related to blood flow. ${ }^{10)}$ Also the incredible nutritional and medicinal value of bee pollen has been known for thousands of years. Bee pollen is a

Corresponding author: Department of Food \& Nutrition, Gachon University, Incheon 406-799, Korea, Tel: +82-32820-4223, Fax: +82-32-820-4220, E-mail: jangjs@gachon.ac.kr Received: 31 July 2012, Revised: 14 October 2012, Accepted: 7 January 2013 
mixture of natural flower pollen, nectar and bee enzymes. Further, it contains sugars, proteins, lipids, vitamins, and flavonoids. ${ }^{11-13)}$ Recently, bee pollen has received special attention due to its potential therapeutic benefits. For example, it has been shown to play positive roles in promoting the growth of endocrine glands and enhancing secretory functions. In this study, we investigated the effect of Korean gastrodia and bee pollen on testosterone production in Sprague-Dawley rats.

\section{Materials and Methods}

\section{Sample}

Mature Gastrodia ( $G$. etata BL.) used in the present study was purchased from Gyeongdong Yangnyeong Market of Seoul (Korea). Also pollens of acorn and Siberian gooseberry were obtained from the Korea Apicultural Cooperative Federation (Yangbong Nonghyup) of Gyeonggi-do. Samples were lyophilized, and ground into powder for animal testing (Fig. 1).

\section{Animals}

Six-week-old male rats of the Sprague-Dawley (SD) strain were purchased from SAMTAKO Bio Korea (Osan, Korea). Six rats were housed per cage in polysulfone rat cages. The animal room was maintained at $22^{\circ} \mathrm{C}$ and $50 \%$ humidity under a $12 \mathrm{~L}$ : $12 \mathrm{D}$ cycle. Animals were allowed to access to rodent chow (SAMTAKO Bio Korea) and sterilized water ad libitum. After 1 week, animals were randomly divided into four groups. Each group constituted of six rats fed a diet of various additives for 4 weeks: control rats fed basal diet, treatment rats fed basal diet and $250 \mathrm{mg} / \mathrm{kg} /$ day (body weight) powder of gastrodia, acorn pollen and Siberian gooseberry pollen, respectively. Average body weight of SD rats was $200 \sim 250 \mathrm{~g}$ at the beginning of the experiment.

\section{Testosterone concentration}

Animals were sacrificed after fasting for 16 hours before the end of the experiment. Blood serum was taken from the abdominal vein after incision of the abdomen under anesthesia with ether, followed by separation by centrifugation for $15 \mathrm{~min}$ at $2500 \mathrm{rpm}$. The testosterone concentrations of serum were analyzed at Green Cross Clinical Laboratory (Yongin, Korea) using testosterone-specific ELISA.

\section{Statistical analysis}

All statistical analysess were performed using PASW software version 18.0 (SPSS Inc., Chicago, Illinois). Data from animal experiments are presented as the mean $\pm \mathrm{SD}$ and were subjected to one-way analysis of variance (ANOVA), followed by Duncan's new multiple-range test. A p-value of $<0.05$ was accepted as being statistically significant.

\section{Results and Discussion}

\section{Effect on body weight}

Body weights change in SD rats between the treatment group and control group were shown in Table 1. It was observed that the average body weight for 4 weeks in the control group was $375 \pm 2 \mathrm{~g}$, $358 \pm 3 \mathrm{~g}$ for gastrodia composition, $354 \pm 2 \mathrm{~g}$ and $367 \pm 8 \mathrm{~g}$ for acorn pollen and Siberian gooseberry pollen composition, respectively. There were no differences in body weight before, during, or after the experiment among rats with gastrodia or bee pollens treatments and the control group.

\section{Change of food consumption}

The amount of daily diet for the experiments was $200 \mathrm{~g}$ per cage. After 24 hours of feeding, we

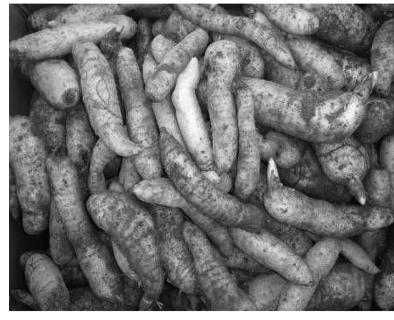

Gastrodia

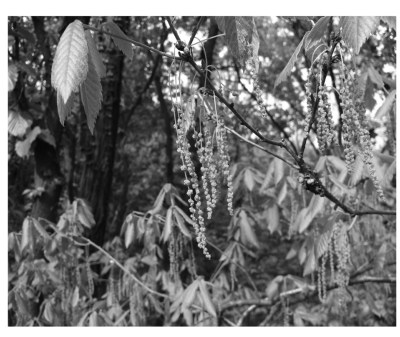

Acorn pollen

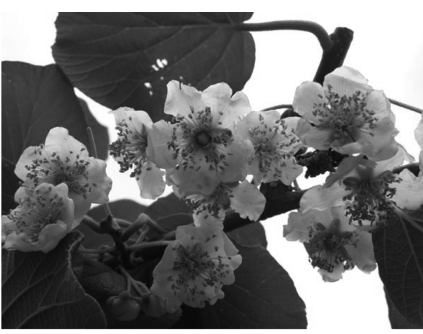

Siberian gooseberry pollen

Fig. 1. Materials used in this study. 
Table 1. Body weight changes in SD rats fed or not fed Gastrodia or bee pollens for 4 weeks

\begin{tabular}{|c|c|c|c|c|}
\hline \multirow{3}{*}{ Materials } & \multicolumn{4}{|c|}{ Body weight (g) } \\
\hline & \multicolumn{4}{|c|}{ Weeks } \\
\hline & 1 & 2 & 3 & 4 \\
\hline $\mathrm{NC}^{1)}$ & $272 \pm 1$ & $309 \pm 2$ & $350 \pm 2$ & $375 \pm 2$ \\
\hline Gastrodia & $272 \pm 1$ & $308 \pm 1$ & $343 \pm 2$ & $358 \pm 3$ \\
\hline Acorn pollen & $272 \pm 1$ & $306 \pm 2$ & $340 \pm 2$ & $354 \pm 2$ \\
\hline $\begin{array}{l}\text { Siberian gooseberry } \\
\text { pollen }\end{array}$ & $273 \pm 1$ & $315 \pm 9$ & $349 \pm 8$ & $367 \pm 8$ \\
\hline
\end{tabular}

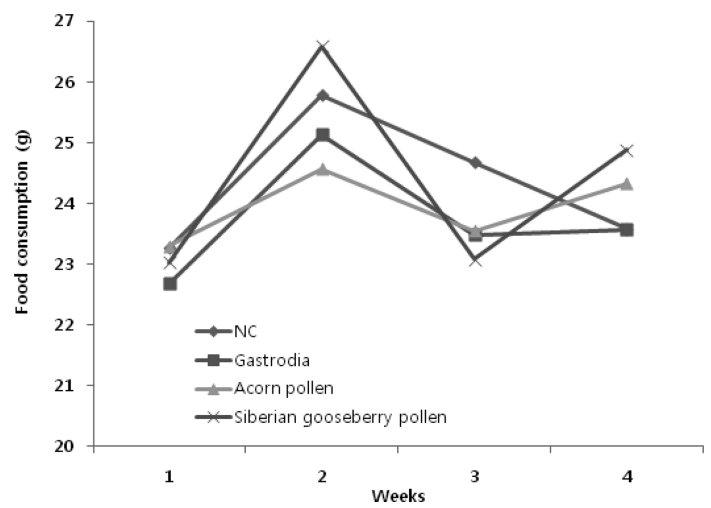

Fig. 2. Food consumption changes of SD rats fed or not fed Gastrodia or bee pollens for 4 weeks. NC, Negative control.

subtracted the remaining amount of food in each cage from $200 \mathrm{~g}$. Then, each of the amounts was divided by the number of animals per cage in order to obtain the quantity of feed intake per rat.

Fig. 2 represents the food consumption change of SD rats between the treatment group and control group. It shows that average food consumption in SD rats for 4 weeks in the control was $23.6 \mathrm{~g}, 23.6 \mathrm{~g}$ for gastrodia composition, $24.3 \mathrm{~g}$ and $24.9 \mathrm{~g}$ ascorn pollen and Siberian gooseberry pollen composition, respectively. The result shows no significant difference in food intake between the groups.

\section{Change of water consumption}

Total sum of water consumption was calculated by subtracting the residual volume of water after 24 hours from the initial volume of given water $(500 \mathrm{~m} l)$. The water intake quantity by each rat is the quotient of total water intake quantity divided by the number of animals per cage.

Water consumption of SD rats fed or not fed gastrodia or bee pollen for 4 weeks was shown in Fig. 3. In the case of the control, it was shown that the average water consumption for 4 weeks was $38.3 \mathrm{~m} l$ in the control group, $35.0 \mathrm{~m} l$ of gastrodia treatment, $33.3 \mathrm{~m} l$ and $33.3 \mathrm{~m} l$ of acorn pollen and Siberian gooseberry pollen treatment, respectively. There was no difference in water intake between the treatment group and control group.

\section{Effect of testosterone concentrations}

To investigate the effects of gastrodia and bee pollen on testosterone production in mouse, male rats were treated with gastrodia, acorn pollen and Siberian gooseberry pollen, respectively. The results are presented in Fig. 4. The testosterone secretion

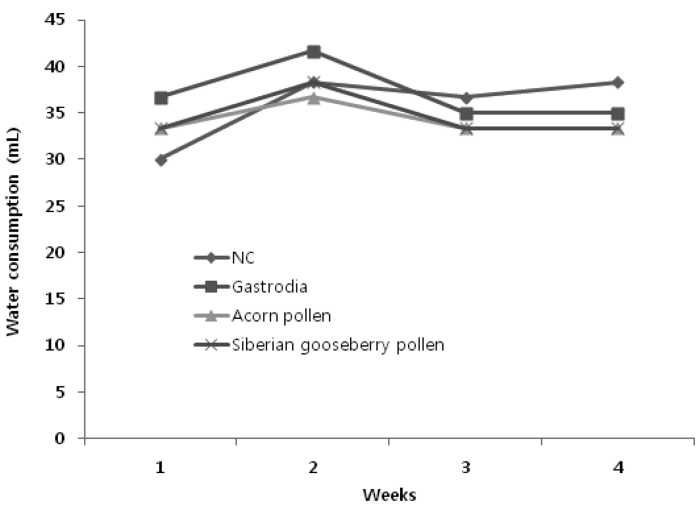

Fig. 3. Water consumption changes of SD rats fed or not fed Gastrodia or bee pollens for 4 weeks. NC, Negative control.

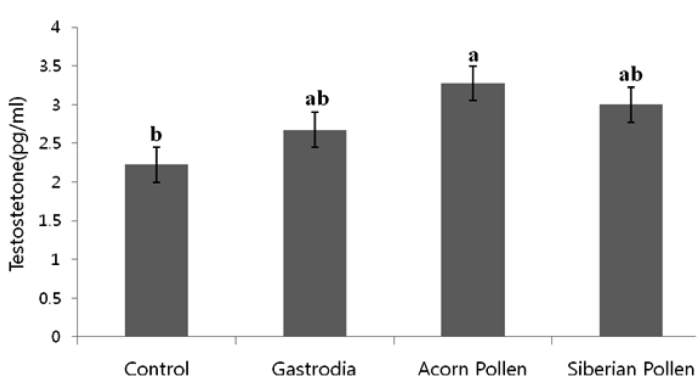

Fig. 4. Serum testosterone concentration in SD rats fed Gastrodia or bee pollens for 4 weeks. The results are represented as mean $\pm \mathrm{SD}$ of three different observations and compared control bu using Duncan's LSD test. Different letters above the bars are significantly different $(\mathrm{p}<0.05)$. 
levels in serum of male rats were increased by gastrodia, acorn pollen, and Siberian gooseberry pollen $(2.68,3.00$, and $3.28 \mathrm{pg} / \mathrm{ml}$, respectively) compared to the control group $(2.23 \mathrm{pg} / \mathrm{ml})$. Gastrodia is used in orthomolecular medicine with high doses of vitamins, minerals and nutritional supplements to treat very complex diseases. Sheen and Chen $(2012)^{14)}$ observed that the water extract of Gastrodia eleta had antidepressant effects in Sprague-Dawley rats. On the other hand, bee pollen has been used as a dietary supplement or culinary ingredient for improving health since ancient times. Melita et al. $(1978)^{15)}$ isolated sex hormones of bees from pine tree pollen (Pinus nigra) and identified testosterone, epitestosterone, androstenedione, and progesterone. Bahmanpour et al. $(2006)^{16)}$ reported that the testosterone level of blood increases in animals treated with palm tree pollen (Phoenix dactylifera).

Our data showed that gastrodia, acorn pollen, and Siberian gooseberry pollen stimulated testosterone production in male rats. Moreover, acorn pollen could also significantly induce testosterone secretions ( $\mathrm{p}<$ 0.05 ), compared to the control group, which is in agreement with the above findings.

In conclusion, we found that gastrodia, acorn pollen, and Siberian gooseberry pollen, especially acorn pollen might be developed as an effective complementary medicine for the treatment of reproductive problems caused by low testosterone levels in human males.

\section{Conclusions}

We investigated the effect of Korean gastrodia and bee pollen on testosterone production in SpragueDawley rats. It was observed that the average body weight for 4 weeks in the control group were $375 \pm$ $2 \mathrm{~g}, 358 \pm 3 \mathrm{~g}$ for gastrodia composition, $354 \pm 2 \mathrm{~g}$ and $367 \pm 8 \mathrm{~g}$ acorn pollen and Siberian gooseberry pollen composition, respectively. The foowd consumption change of SD rats between the treatment group and control group. It shows that average food consumption in SD rats for 4 weeks in the control was $23.58 \mathrm{~g}, 23.6 \mathrm{~g}$ for gastrodia composition, $24.3 \mathrm{~g}$ and $24.9 \mathrm{~g}$ ascorn pollen and Siberian gooseberry pollen composition, respectively. In the case of the control, it was shown that the average water consumption for 4 weeks was $38.3 \mathrm{ml}$. Water consumption of gastrodia treatment was utilized for $35.0 \mathrm{ml}$. Water consumption of acorn pollen and Siberian gooseberry pollen treatment were utilized for $33.3 \mathrm{ml}$ and $33.3 \mathrm{ml}$, respectively. The testosterone secretion levels in serum of male rats were increased by gastrodia, acorn pollen, and Siberian gooseberry pollen (2.68, 3.00 , and $3.28 \mathrm{pg} / \mathrm{ml}$, respectively) compared to the control group $(2.23 \mathrm{pg} / \mathrm{m} l)$.

So we consider that gastrodia and bee pollens can be a nature cure for low testosterone if more research are carried.

\section{References}

1. Saez JM. Leydig cells: endocrine, paracrine and autocrine regulation. Endocr Rev. 1994; 574-626.

2. Sinclair S. Male infertility: nutritional and environmental considerations. Altern Med Rev. 2000; 2838.

3. Roscoe WA, Barr KJ, Mhawi AA, Pomerantz DK, Kidder GM. Failure of spermatogenesis in mice lacking connexin 43. Biol Reprod. 1994; 829-838.

4. Huff DS, Snyder III HM, Rusnack SL, Zderic SA, Carr MC, Canning DA. Hormonal therapy for the subfertility of cryptorchidism. Horm Res. 2001; 38-40.

5. Crimmel AS, Conner CS, Monga M. Withered Yang: a review of traditional Chinese medical treatment of male infertility and erectile dysfunction. J Androl. 2001; 173-182.

6. Ryu KS, Lee HS, Kim KY, Kim MJ, Lee KG. Testosterone secretion effect according to the growth stage of silkworm (Bombyx mori L.). Int J Indust Entomol. 2010; 20: 75-77.

7. Ryu KS, Lee HS, Kang PD, Kim KY, Kim MJ, Oh HG, Kang PD. Secretion effect of estrogen of different growth stages of silkworm (Bombyx mori L.). Int J Indust Entomol. 2011; 22: 17-20.

8. Hong IP, Choi YS, Woo SO, Han SM, Kim HK, Lee MR, Nam SH, Ha NG. Stimulatory effect of Cordyceps militaris on testosterone production in male mouse. Kor J Mycol. 2011; 39: 148-150.

9. Hsu CC, Huang SJ, Tsai CC, Huang BM. In vivo and in vitro stimulatory effects of Cordyceps sinensis on testosterone production in mouse Leydig cells. Life Sci. 2003; 73: 2127-2136

10. Silva TMS, Camara CA, Lins ACS, Barbosa-Filho JM, Silva EMS, Freitas BM. Chemical composition and free radical scavenging activity of pollen loads from stingless bee Melipona subnitida Ducke. J Food Compos Anal. 2006; 19: 507-511. 
11. Liu CL, Liu MC, Zhu PL. Determination of Gastrodin, $p$-Hydroxybenzyl Alcohol,Vanillyl Alcohol, $p$-Hydroxylbenzaldehyde and Vanillin in Tall Gastrodia Tuber by High-Performance Liquid Chromatography. Chromatographla, 2002; 55: 317-320.

12. Tomas-Lorente F, Garcia-Grau MM, Nieto JL, Tomas-Barberan, FA. Flavonoids from CistusLadanifer bee pollen. Phytochemistry 1992; 1: 2027-2029.

13. Ukiya M, Akihisa T, Tokuda H, Koike K, Takayasu J, Okuda $\mathrm{H}$. Isolation, structural elucidation, and inhibitory effects of terpenoid and lipid constituents from sunflower pollen on Epstein-Barr virus early antigen induced by tumor promoter,(.) TPA. J Agric Food Chem. 2003; 51: 2949-2957.

14. Sheen L and Chen E. Antidepressant effects of Gastrodia elata Bl. at the genomic level. BMC Complementary and Alternative Medicine. 2012; 12(1): 35

15. Melita SK, Melita T, Dragutin K. Sex hormones and corticosteroids in pollen of Pinus nigra. Phytochemistry. 1979; 18(2): 345-346.

16. Bahmanpour S, Talaei T, Vojdani Z, Panjehshahin MR, Poostpasand A, Zareei S, Ghaeminia M. Effect of Phoenix Dactylifera Pollen on Sperm Parameters and Reproductive system of Adult Male Rats. Iran J Med Sci. 2006; 31(4): 208-212. 